Report

\title{
Longer-term consequences of anger expression in negotiation: Retaliation or spillover?
}

\author{
Gerben A. Van Kleef*, Carsten K.W. De Dreu \\ Department of Psychology, University of Amsterdam, The Netherlands
}

\section{A R T I C L E I N F O}

\section{Article history:}

Received 3 December 2008

Revised 9 March 2010

Available online 27 March 2010

\section{Keywords:}

Anger

Negotiation

Cooperation

Longer-term consequences

Social value orientation

Apologies

\begin{abstract}
A B S T R A C T
Negotiators often concede to angry partners. But what happens when they meet again? According to the spillover hypothesis, negotiators demand less from previously angry partners because they perceive them as tough. According to the retaliation hypothesis, negotiators demand more from previously angry partners because of negative impressions and a desire to get even. Experiment 1 showed that participants demanded less in later negotiations when their partner in a previous negotiation had expressed anger (rather than no emotion) and the later negotiation was with the same (rather than a different) partner. Consistent with the spillover hypothesis, this effect was mediated by inferences regarding the partner's toughness. Experiment 2 showed that apologies reduce the negative effects of anger on impressions and desire for future interaction. Behavioral reactions were moderated by social value orientation: extending the established might/morality effect, prosocial participants responded cooperatively to an apology, whereas proselfs responded competitively.
\end{abstract}

(c) 2010 Elsevier Inc. All rights reserved.

\section{Introduction}

Emotions are part and parcel of conflict and negotiation, influencing not only the people who experience them but also those who observe them. Anger in particular stands out as a pervasive driver of negotiation and dispute resolution behavior (Adler, Rosen, \& Silverstein, 1998; Allred, 1999). Anger arises when an individual's goals are frustrated and she/he blames another person for it (Frijda, 1986; Lazarus, 1991), and it triggers a tendency to "move against" the source of frustration (Fischer \& Roseman, 2007; Lazarus, 1991). Expressions of anger in negotiation do not always have the effects one might intuitively expect. Whereas many predict anger to beget anger, thus creating an escalatory spiral of increasingly hostile feelings and competitive exchanges, research has revealed that negotiators often concede in the face of a counterpart's anger (Van Kleef, De Dreu, \& Manstead, 2010). It thus appears that expressing anger may help to extract concessions and secure an advantageous agreement.

A limitation of prior research is that it has focused exclusively on single-shot interactions and ignored longer-term effects. Friends, spouses, employees in large organizations, and diplomats in the political arena often negotiate on repeated occasions, yet we know very little about the longer-term consequences of

\footnotetext{
* Corresponding author. Address: University of Amsterdam, Department of Social Psychology, Roetersstraat 15, 1018 WB Amsterdam, The Netherlands. Fax: +31 20 6391896.

E-mail address: g.a.vankleef@uva.nl (G.A. Van Kleef).
}

expressing anger. Do the effects of anger spill over to future interactions, making the other conciliatory on subsequent occasions as well? Do they wear off over time? Or do expressions of anger backfire in subsequent negotiations, rendering counterparts relatively demanding in the longer run?

To address these questions, we draw on the emotions as social information (EASI) model and previous research on emotions in negotiations. This work inspires two competing hypotheses regarding the longer-term effects of anger expression in negotiation. According to the EASI model (Van Kleef, 2009; Van Kleef et al., 2010), emotional expressions provide information about the expresser's feelings, intentions, and social orientation (see also Keltner \& Haidt, 1999). In particular, because of the associated "moving against" tendency, expressions of anger signal toughness and power (Frank, 1988; Tiedens, 2001). Such inferences carry strategic importance in negotiations. Negotiators with an angry partner tend to infer that the other has tough limits and is "hard to get," which often leads them to moderate their claims to prevent impasse (Sinaceur \& Tiedens, 2006; Van Kleef, De Dreu, \& Manstead, 2004a, 2004b).

Although never tested, it is conceivable that such inferences spread to future encounters. Research on the fundamental attribution error indicates that people tend to attribute others' behavior to internal rather than external causes (Ross, 1977). A negotiation study by Morris, Larrick, and Su (1999) demonstrated that even though a partner's behavior was determined by his or her bargaining position, participants attributed the other's toughness to personality characteristics, and these attributions 
informed behavior in subsequent interactions with that person. We propose that inferences drawn from others' emotions may similarly spread from one encounter to the next. Thus, a negotiator dealing with an angry counterpart may infer that the other is tough and ambitious, and this inference may generalize to inform the negotiator's strategy in subsequent negotiations with the counterpart. Accordingly, we advance the spillover hypothesis: negotiators who dealt with an angry (rather than non-emotional) counterpart in a previous negotiation demand less in a subsequent negotiation when dealing with the same (rather than a different) counterpart because they infer that the other has tough limits and may be easily provoked.

According to the EASI model, emotional expressions also evoke affective reactions in observers that may subsequently influence their behavior (Van Kleef, 2009; Van Kleef et al., 2010). Again, anger is particularly interesting because it arouses strong negative sentiments in targets and hurts interpersonal relations (Axelrod, 1984; Clark, Pataki, \& Carver, 1996; Van Kleef et al., 2009). Expressions of anger may be perceived as violating principles of interactional justice (Van Kleef \& Côté, 2007)-the fairness of interpersonal treatment (Bies \& Moag, 1986). Feelings of injustice in turn breed mutual anger and hostility (Barclay, Skarlicki, \& Pugh, 2005), aggression (Baron, Neuman, \& Geddes, 1999; Kennedy, Homant, \& Homant, 2004), and a desire to get even (Skarlicki \& Folger, 1997). Such retaliatory reactions to anger are especially pronounced in exchange relationships, of which negotiation is a prime example (Clark \& Taraban, 1991; De Dreu, 2010).

Several studies point to the negative reactions that are elicited by expressions of anger in negotiation. Negotiators typically develop a negative impression of angry counterparts (Van Kleef et al., 2004a), become angry themselves (Friedman et al., 2004; Van Kleef et al., 2004a), and are unwilling to engage in future interaction with them (Kopelman, Rosette, \& Thompson, 2006; Van Kleef et al., 2004b). These negative reactions can have detrimental longer-term effects for negotiators who express anger. In an illustrative study, participants engaged in coalition negotiations developed a negative impression of parties who verbally expressed anger, which led them to exclude those parties from a coalition (Van Beest, Van Kleef, \& Van Dijk, 2008). In another study, powerful negotiators became more competitive when they deemed their partner's anger expressions inappropriate (Van Kleef \& Côté, 2007). In short, expressions of anger often fuel a desire to retaliate (especially when the opportunity for revenge arises shortly after the provoking situation; Bies \& Tripp, 2001), which may lead negotiators to adopt a competitive stance (Steinel, Van Kleef, \& Harinck, 2008; Van Dijk, Van Kleef, Steinel, \& Van Beest, 2008). Thus, we propose the retaliation hypothesis: negotiators who dealt with an angry (rather than non-emotional) counterpart in a previous negotiation demand more in a subsequent negotiation when dealing with the same (rather than a different) counterpart.

\section{Experiment 1}

To test these competing hypotheses, we engaged participants in two subsequent computer-mediated negotiations. We employed a verbal manipulation of anger to allow for optimal experimental control (note that verbal and nonverbal expressions of anger have similar effects on negotiation behavior; Van Kleef et al., 2010). In Negotiation 1, participants were confronted with a counterpart who expressed either anger or no emotion. In Negotiation 2, participants were paired with the same or a different partner, who in this case expressed no emotions. We assessed participants' appraisals of the partner's limits to test whether perceptions of toughness in Negotiation 1 can account for demands in Negotiation 2, as implied by the spillover hypothesis. We measured impressions of the counterpart to test whether these mediate demands in Negotiation 2 , as suggested by the retaliation hypothesis.

\section{Method}

\section{Participants and design}

Seventy-four students (49 females, 25 males; $M_{\text {age }}=20.23$ years, $S D=2.33$ ) participated for course credit. We used a 2 (partner's emotion in Negotiation 1: anger vs. no emotion) $\times 2$ (partner in Negotiation 2: same vs. different) design.

\section{Procedure}

Participants sat in separate cubicles in front of a computer, which presented all instructions, questionnaires, and tasks. They learned that they would engage in a computer-mediated negotiation with another participant (whose behavior was in fact simulated by the computer).

Negotiation 1. We used an existing computerized distributive negotiation task (for details, see Van Kleef et al., 2004a, 2004b). In the current version, participants assumed the role of seller of mobile phones, negotiating price, warranty, and service with a buyer. Participants learned that the better they negotiated, the greater their chance of winning a EUR 50 prize. The buyer (the computer) made the first offer, and throughout the negotiation the buyer's offers followed a standardized pattern (see Van Kleef et al., 2004a). After the fourth round participants read that the negotiation was "interrupted" for some questions, leaving open the possibility that the negotiation would continue later.

Manipulation of counterpart's emotional expression. After the first round, participants in the anger condition received the following message from their partner: "This offer makes me really angry, I am going to offer [next offer]"). After the third round, participants read "This is really getting on my nerves, I am going to offer [next offer]." Participants in the control condition only received the neutral information ("I am going to offer ..."). This anger manipulation has been extensively pre-tested and used in previous research. The angry statements are perceived as credible and realistic (Van Kleef et al., 2004a, 2004b), and they produce similar effects as manipulations involving pictures of angry faces (Pietroni, Van Kleef, De Dreu, \& Pagliaro, 2008), video clips of anger expressions (Côté, Van Kleef, \& Hideg, submitted for publication), and face-to-face expressions of anger (Sinaceur \& Tiedens, 2006).

Partner manipulation. Participants read that, in the interest of time, they would proceed with the next task, which was Negotiation 2. In the same-partner condition, participants read that they would negotiate with the same partner as before; in the different-partner condition they would be paired with a different partner. We emphasized that the two negotiations were unrelated.

Negotiation 2. The second negotiation was adapted from Pietroni et al. (2008). To stress that the two negotiations were unrelated we changed the structure of the task in several ways: participants made the first offer; there were two issues rather than three; the context and subject were different; the payoffs were different; and the structure of the payoff schedule was reversed. These changes reinforced the cover story that the second negotiation would "enhance generalizability of the findings across different types of negotiations." Besides these changes, the procedure of Negotiation 2 was identical to that of Negotiation 1. Importantly, 
it was stressed that participants' chances to obtain a prize in either negotiation were independent of one another. ${ }^{1}$

In Negotiation 2 (for details, see Pietroni et al., 2008), participants imagined working for a computer company selling assembled computers for fixed prices. The characteristics of the computer parts (i.e., monitor and hard disk) were subject to negotiation. As shown in Table 1, hard disk yielded between 1 and 33 points, and monitor yielded between 1 and 17 points. In total participants could thus earn a maximum of 50 points.

Participants made the first proposal. Over the course of the negotiation the buyer proposed the following deals (for monitorhard disk; see Table 1): 2 - 2 (after participant's first offer), $3-2$ (after second offer), and 4-3 (after third offer). An offer by the participant was accepted if it matched the computer's next offer. In Negotiation 2, the buyer expressed no emotions.

Dependent measures. Participants' demands in each round were combined into an index of average demands in the negotiation (see Hilty \& Carnevale, 1993).

Estimates of the partner's limits in Negotiation 2 were measured using four items (adapted from Van Kleef et al., 2004a), two for each issue ("What do you think was the buyer's lowest acceptable offer on [hard disk/monitor]?"; "How far do you think the buyer would be prepared to go on [hard disk/monitor]?"). Responses could range from 1 (indicating an extremely high limit) to 9 (indicating an extremely low limit; see Table 1 ). The items formed a reliable scale $(\alpha=.70)$.

Impressions of the partner were assessed by eight items taken from Van Kleef et al. (2004a) pertaining to perceptions of the partner's hostility, trustworthiness, immorality, cooperativeness, unreasonableness, stubbornness, friendliness, and general impression $(1=$ strongly disagree to $9=$ strongly agree). Negative items were recoded to create a positive-impression index $(\alpha=.85)$.

The anger manipulation was checked after Negotiation 1 , using three items ("During the negotiation, the buyer appeared to be [angry/irritated/aggravated]"; $1=$ strongly disagree to $9=$ strongly agree; $\alpha=.96$ ). Finally, after Negotiation 2, participants indicated whether they had negotiated with the same or a different person.

\section{Results}

\section{Manipulation checks}

Participants in the angry partner condition rated the partner as more angry $(M=7.41, S D=1.39)$ than those in the non-emotional condition $(M=3.43, S D=1.65), F(1,71)=126.28, p<.001, \eta^{2}=.64$. There was no main or interaction effect involving the partner manipulation (both $F s<1, n s$ ).

All participants correctly identified their partner in Negotiation 2 as the same or different from Negotiation 1 .

\section{Demands}

A main effect of partner's emotion in Negotiation 1 on demands in Negotiation 2 revealed that participants made smaller demands when the partner in Negotiation 1 had expressed anger $(M=34.07$, $S D=4.61)$ rather than no emotion $(M=37.29, \quad S D=6.08)$,

\footnotetext{
${ }^{1}$ This means that good or bad outcomes in Negotiation 1 could not be compensated for in Negotiation 2. This renders alternative explanations in terms of compensation for failure in Negotiation 1 less likely. Indeed, exploratory analyses of three items measuring compensation motives ("In the second negotiation, I wanted to compensate for my performance in the first negotiation"; "I wanted to do better in the second negotiation"; "I wanted to set things straight in the second negotiation") revealed no effects of Emotion or Partner. This suggests that any motivation to compensate for failure in the first negotiation cannot account for the observed differences between conditions.
}

Table 1

Participants' payoff chart in the second Negotiation.

\begin{tabular}{cccccc}
\hline Level & \multicolumn{2}{c}{ Quality of monitor } & & \multicolumn{2}{c}{ Quality of hard disk } \\
\cline { 2 - 3 } & Monitor type & Payoff & & Hard disk type & Payoff \\
\hline 1 & Monitor A & 1 & Hard disk A & 1 \\
2 & Monitor B & 3 & Hard disk B & 5 \\
3 & Monitor C & 5 & Hard disk C & 9 \\
4 & Monitor D & 7 & Hard disk D & 13 \\
5 & Monitor E & 9 & Hard disk E & 17 \\
6 & Monitor F & 11 & Hard disk F & 21 \\
7 & Monitor G & 13 & Hard disk G & 25 \\
8 & Monitor H & 15 & Hard disk H & 29 \\
9 & Monitor I & 17 & Hard disk I & 33 \\
\hline
\end{tabular}

$F(1,71)=6.45, p<.013, \eta^{2}=.08$. There was no main effect of the partner manipulation $(F<1, n s)$. Most importantly, we found a significant Emotion $\times$ Partner interaction, $F(1,71)=6.30, p<.014$, $\eta^{2}=.08$ (see Table 2 for Ms and SDs). Participants who dealt with the same partner in Negotiation 2 demanded less when the other had expressed anger rather than no emotion before, whereas the demands of participants who dealt with a different partner were not affected by the partner's emotion. This pattern (see Fig. 1) supports the spillover hypothesis.

\section{Impressions}

As anticipated, participants with an angry partner developed a less favorable impression of their partner $(M=3.92, S D=1.29)$ than those with a non-emotional partner $(M=5.48, S D=1.06), F(1,71)=$ $31.88, p<.001, \eta^{2}=.31$. There were no effects involving partner $(F s<1, n s)$.

\section{Inferences regarding partner's limits}

Participants who had an angry counterpart in Negotiation 1 estimated the other's limits in Negotiation 2 to be higher $(M=4.33$, $S D=0.67)$ than did those who had dealt with a non-emotional counterpart $(M=4.91, S D=0.91), F(1,71)=9.79, p<.001, \eta^{2}=.12($ recall that, from the partner's perspective, lower numbers reflect more ambitious limits; see Table 1$)$. Moreover, there was a significant Emotion $\times$ Partner interaction, $F(1,71)=5.26, p<.025, \eta^{2}=.07$ (see Table 2): estimates of the other's limits were influenced by partner's emotion in the same-partner condition, but not in the different-partner condition.

\section{Mediation analysis}

To test whether the Emotion $\times$ Partner interaction on demands is mediated by appraisal of the partner's limits, as suggested by the spillover hypothesis, we conducted mediated regression analyses

Table 2

Means and standard deviations (in parentheses) of emotion by Partner interaction on appraisal of partner's limits and demands in Negotiation 2 (Experiment 1).

\begin{tabular}{lcc}
\hline Partner in Negotiation 2 & \multicolumn{2}{c}{ Opponent's emotion in Negotiation 1} \\
\cline { 2 - 3 } & \multicolumn{1}{c}{ Anger } & No emotion \\
\hline Appraisal of partner's limits & & \\
Same & $3.99(0.63)_{\mathrm{a}}$ & $4.96(0.91)_{\mathrm{b}}$ \\
Different & $4.69(0.50)_{\mathrm{b}}$ & $4.84(0.93)_{\mathrm{b}}$ \\
Demands in Negotiation 2 & & \\
Same & $32.11(4.06)_{\mathrm{a}}$ & $38.29(7.29)_{\mathrm{b}}$ \\
Different & $36.15(4.34)_{\mathrm{b}}$ & $36.18(4.32)_{\mathrm{b}}$ \\
\hline
\end{tabular}

Note: Means within a row and means within a column not sharing a subscript differ at $p<.05$ according to simple-effects analyses. Note that for the limit measure, lower numbers reflect more ambitious limits. 


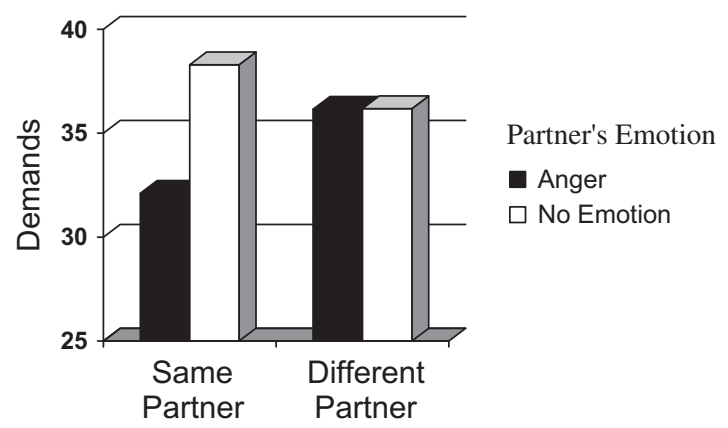

Fig. 1. Demands in Negotiation 2 as a function of partner's emotion in Negotiation 1 and partner in Negotiation 2 (Experiment 1).

(see Kenny, Kashy, \& Bolger, 1998). Step 1 (Emotion $\times$ Partner interaction on demands, $\beta=-.27, t=-2.51, p<.015)$ and Step 2 (Emotion $\times$ Partner interaction on appraisal of partner's limits, $\beta=-.24, t=-2.29, p<.025)$ logically confirmed the ANOVA results. In Step 3 we simultaneously entered the independent variables (emotion, partner, and their interaction) and the mediator (limits) to predict demands. This yielded a significant effect of limits, $\beta=.47, t=4.28, p<.001$, and rendered the Emotion $\times$ Partner interaction non-significant $(\beta=-.16, t=-1.58, p=.12)$. A Sobel test showed that the indirect path was significant, $Z=2.02$, $p<.05$. Thus, the interactive effect of emotion and partner on demands is fully mediated by inferences regarding the partner's limits.

\section{Discussion}

Negotiators made smaller demands in Negotiation 2 when their partner in Negotiation 1 had expressed anger rather than no emotion and when they dealt with the same rather than a different partner in Negotiation 2. Supporting the spillover hypothesis, this effect was mediated by inferences regarding the partner's toughness: negotiators who dealt with the same partner in Negotiation 2 estimated the partner's limits as tougher when the partner had previously expressed anger rather than no emotion, and therefore they placed relatively low demands.

Although expressions of anger instilled negative impressions, these negative impressions did not lead participants to make tough demands in Negotiation 2. (In fact, positivity of impressions was positively correlated with demands, $r=.36, p<.01$, not negatively as would be expected based on the retaliation hypothesis; accordingly, controlling for impressions did not remove the Emotion $\times$ Partner interaction on demands, $F[1,70]=6.35, p<.014$.) Still, negative impressions may reduce the likelihood of future interaction when negotiators are free to choose their negotiation partner (Friedman et al., 2004; Tinsley, O'Connor, \& Sullivan, 2002; Van Beest et al., 2008). It is therefore interesting to explore strategies that capitalize on the beneficial longer-term effects of anger (eliciting concessions in future negotiations with the same partner) without bringing about the negative consequences (negative impressions and reduced likelihood of future deals). In Experiment 2 we explored one such strategy: apologizing.

\section{Experiment 2}

We examined whether apologizing may alleviate the negative effects of anger on impressions and desire for future interaction, while preserving the positive effects on concessions. Apologies signal interpersonal sensitivity and a willingness to appreciate another person's perspective-important relationship repairing qualities (Steiner, 2000). Apologizing after a transgression may reduce blame and punishment (Darby \& Schlenker, 1982), increase forgiveness (Bachman \& Guerrero, 2006), reduce aggression (Ohbuchi, Kameda, \& Agarie, 1989), and enhance liking (Darby \& Schlenker, 1982; Ohbuchi et al., 1989). We therefore hypothesized that negotiators would develop more favorable impressions of and would be more willing to engage in future interaction with partners who apologized after expressing anger compared to partners who did not apologize.

Apologizing does not necessarily elicit cooperative behavior; sometimes it backfires (Philpot \& Hornsey, 2008; Struthers, Eaton, Santelli, Uchiyama, \& Shirvani, 2008). Whether an apology fosters cooperation depends, to a large extent, on the recipient's interpretation of the apology (Tavuchis, 1991). Is it taken as a sign of interpersonal sensitivity or as a sign of weakness? We suspect that the answer to this question is partly rooted in the recipient's social value orientation (SVO)-the preference for particular outcome distributions between self and others (Liebrand \& Van Run, 1985; Messick \& McClintock, 1968; Van Lange, Otten, De Bruin, \& Joireman, 1997). The most widely studied and most commonly observed are the prosocial and the proself orientation (Van Lange, 1999). Prosocial orientation is defined in terms of maximizing equality and joint outcomes; proself orientation is defined in terms of enhancing outcomes for self regardless of, or even at the expense of, others' outcomes (De Cremer \& Van Lange, 2001; De Dreu \& Van Kleef, 2004; De Dreu \& Van Lange, 1995; Olekalns \& Smith, 1999; Steinel \& De Dreu, 2004; Van Kleef \& Van Lange, 2008).

Although prosocials and proselfs differ on several dimensions, especially pertinent to the present research is the finding that prosocials are more attuned to issues of morality (e.g., honesty, justice, reciprocity), whereas proselfs are more attuned to issues of "might" or potency (e.g., intelligence, power)-the so-called might/morality effect (Liebrand, Jansen, Rijken, \& Suhre, 1986; Van Lange \& Kuhlman, 1994). Because of their greater sensitivity to morality, we hypothesize that prosocials are more likely to reciprocate apologies with cooperation because they appreciate the signs of interpersonal sensitivity and remorse. By contrast, given their focus on might, proselfs should be more likely to respond to apologies with competition because they interpret an apology as a sign of weakness and an opportunity for exploitation.

Method

\section{Participants and design}

Participants $\left(N=103 ; 65\right.$ females, 38 males; $M_{\text {age }}=22.08$ years, $S D=3.62$ ) enrolled in the study for course credit or seven EUR. Independent variables were the partner's emotion in Negotiation 1 (anger-without-apology vs. anger-with-apology vs. no emotion) and the participant's SVO (prosocial vs. proself). All participants negotiated with the same partner in Negotiation 2.

\section{Procedure}

SVO. We used the well-validated triple-dominance measure of social values to assess SVO (Van Lange et al., 1997). Participants made decisions in nine "decomposed games," choosing among three different distributions of points between themselves and a hypothetical other (for details, see Van Lange et al., 1997). Table 3 provides some examples. In example 1 , option A provides a greater advantage over the other's outcomes $(480-80=400)$ than option B $(540-280=260)$ or option C $(480-480=0)$. In Option B one's own outcomes are larger (540) than in option A (480) or option C (480). Proselfs prefer these options. Option C is preferred by prosocials because it provides equality and higher joint outcomes $(480+480=960)$ than options $A(480+80=560)$ and $B(540+280=820)$. Using the common criterion of at least six consistent choices, 42 participants were classified as prosocial (40.8\%) and 55 as proself (53.4\%). Six participants (5.8\%) did not make con- 
Table 3

Three examples of decomposed games.

\begin{tabular}{lllllllll}
\hline & \multicolumn{2}{c}{ Example 1 } & & \multicolumn{2}{c}{ Example 2 } & & \multicolumn{2}{c}{ Example 3 } \\
\cline { 2 - 3 } & Self & Other & & Self & Other & & Self & Other \\
\hline Option A & 480 & 80 & & 560 & 300 & & 520 & 520 \\
Option B & 540 & 280 & & 500 & 500 & & 520 & 120 \\
Option C & 480 & 480 & & 500 & 100 & & 580 & 320 \\
\hline
\end{tabular}

sistent choices (i.e., were unclassifiable), and were dropped from the analyses.

After a 10-min filler task participants received instructions for the negotiation, which was presented as an unrelated study. The procedure was similar to Experiment 1, with two exceptions. First, we added the apology manipulation (see below), which was integrated with the emotion manipulation to create three different conditions: anger-without-apology, anger-with-apology, or no emotion. Second, all participants negotiated with the same counterpart in Negotiation 2.

Apology manipulation. After Negotiation 1, participants read: "To conclude the negotiation, you will now get the opportunity to send each other a brief message. You can write anything you want. If you do not want to send a message, just hit enter." In the angerwithout-apology condition and in the no-emotion condition, participants then read "The buyer has not sent a message." In the anger-with-apology condition, participants received one of two brief apologetic statements from the buyer: "Hi! Sorry if I appeared a little rough there, I got a bit carried away by the game. My apologies!"; or "Hi! Sorry if I appeared a little rough there, I'm having a terrible week. My apologies!" We used two different apologetic statements to rule out possible idiosyncrasy effects. Initial analyses revealed no differences between the statements on any of the dependent variables, so we collapsed them into a single condition.

Dependent measures. Besides demands and impressions (see Experiment 1) we measured participants' desire to engage in future interaction with their counterpart using three items taken from Van Kleef et al. (2004b): "I would be interested in negotiating again with this buyer"; "I would like to avoid future negotiation with the buyer," reverse scored; "I would like to do business with the same buyer in the future" $(\alpha=.81)$. The anger check was identical to that of Experiment 1. We checked the apology manipulation using four items ("After the first negotiation, the buyer apologized for his or her behavior"; "The buyer made excuses after the first negotiation"; "The buyer showed remorse"; and "The buyer took responsibility for his or her behavior"; $\alpha=.96$ ).

Results

\section{Manipulation checks}

Anger. Participants perceived more anger in both anger conditions (anger-without-apology: $M=7.02, S D=1.15$; anger-with-apology: $M=6.02, S D=1.57)$ than in the no-emotion condition $(M=3.65$, $S D=1.50), F(2,91)=45.67, p<.001, \eta^{2}=.50$.

Apologies. Participants in the anger-with-apology condition scored higher on the apology check $(M=6.09, S D=1.95)$ than those in the anger-without-apology condition $(M=2.39, S D=1.40)$ and the noemotion condition $(M=2.50, S D=1.75), F(2,91)=52.84, p<.001$, $\eta^{2}=.54$.

\section{Correlations}

Positive impressions and desire for future interaction were positively correlated, $r=.46, p<.001$. Neither impressions $(r=.13$, $p<.18)$ nor desire for future interaction $(r=.12, p<.22)$ correlated significantly with demands.

\section{Demands}

There were no significant main effects of partner's emotion $(F=1.52, p=.23)$ or SVO $(F=2.26, p=.14)$ on demands. Importantly, however, ANOVA revealed the anticipated Emotion $\times$ SVO interaction, $F(2,91)=6.66, p<.002, \eta^{2}=.13$ (see Table 4 for descriptives). Prosocials demanded less from a counterpart who had expressed anger in Negotiation 1 and then apologized than from a counterpart who had expressed no emotion, the angerwithout-apology condition occupying an intermediate position. Proselfs, in contrast, demanded more from a counterpart who had expressed anger and apologized than from a counterpart who had expressed anger without apologizing, the non-emotional control condition falling in between (see Fig. 2).

\section{Impressions}

Impressions were less favorable in the anger-without-apology condition $(M=3.61, S D=1.25)$ than in the anger-with-apology condition $(M=4.43, S D=0.87)$ and the control condition $(M=4.58$, $S D=1.11$; the latter conditions did not differ), $F(2,91)=9.11$, $p<.001, \eta^{2}=.17$. There was no main effect of SVO $(F<1, n s)$, and no interaction $(F=1.53, p=.22)$. Thus, regardless of SVO, apologizing after an anger expression alleviated the negative effects of the anger on impressions.

\section{Desire for future interaction}

Participants in the anger-without-apology condition were less willing to engage in future interaction with the partner $(M=3.51$, $S D=1.41)$ than those in the anger-with-apology condition $(M=4.42, S D=1.92)$ and the no-emotion condition $(M=4.28$, $S D=1.85$; the latter conditions did not differ), $F(2,91)=3.07$, $p<.05, \eta^{2}=.06$. A main effect of SVO revealed that prosocials were more willing than proselfs to engage in future interaction $(M=4.52, \quad S D=1.77 \quad$ vs. $\quad M=3.81, \quad S D=1.76), \quad F(2,91)=3.79$, $p<.05, \eta^{2}=.07$. There was no significant interaction $(F<1, n s)$.

\section{Table 4}

Means and standard deviations (in parentheses) of emotion/apology by SVO interaction on demands in Negotiation 2 (Experiment 2).

\begin{tabular}{llll}
\hline & \multicolumn{3}{c}{ Opponent's emotion and apology in Negotiation 1 } \\
\hline Participant's SVO & Anger & Anger + apology & No emotion \\
Prosocial & $33.09(8.51)_{\mathrm{a}}$ & $29.36(6.33)_{\mathrm{a}}$ & $36.81(4.31)_{\mathrm{b}}$ \\
Proself & $32.35(7.29)_{\mathrm{a}}$ & $38.21(5.99)_{\mathrm{b}}$ & $35.13(5.86)_{\mathrm{ab}}$ \\
\hline
\end{tabular}

Note: Means within a row and means within a column not sharing a subscript differ at $p<.05$ according to simple-effects analyses and (for comparisons within rows) Duncan tests.

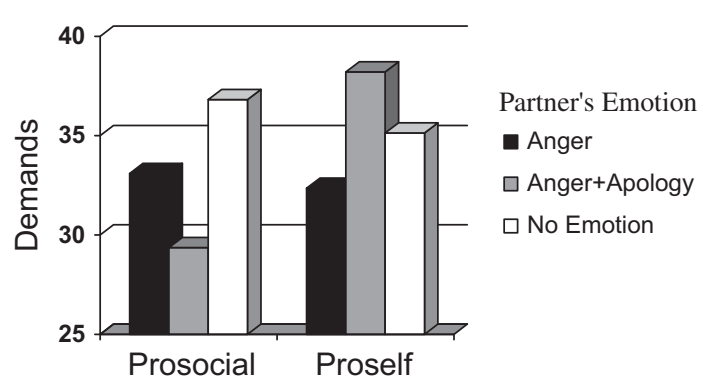

Fig. 2. Demands in Negotiation 2 as a function of partner's emotion and apology in Negotiation 1 and participant's social value orientation (Experiment 2). 


\section{Discussion}

Apologizing after expressing anger can alleviate some of the negative consequences of anger. Participants developed more favorable impressions of and were more willing to engage in future interaction with partners who apologized after getting angry. At the behavioral level, the effects of apologies were moderated by SVO. As predicted based on the might/morality effect (Liebrand et al., 1986; Van Lange \& Kuhlman, 1994), prosocials were most cooperative in Negotiation 2 when their partner had expressed anger and then apologized, whereas proselfs were most competitive in that condition.

\section{General discussion}

We explored the longer-term consequences of anger expression in negotiation. Supporting our spillover hypothesis, participants in Experiment 1 made smaller demands when their partner in a previous negotiation had expressed anger rather than no emotion and they negotiated with the same rather than a different partner. Negotiators who dealt with the same partner judged the partner's limits as more ambitious when the partner had previously expressed anger rather than no emotion, and this led them to place relatively low demands. Experiment 2 replicated the spillover effect and demonstrated that apologizing can alleviate the negative relational consequences of anger expression. Participants whose partner apologized after expressing anger developed more favorable impressions and were more willing to engage in future negotiations with the partner than those with non-apologetic partners. In fact, impressions were just as positive as those of non-angry partners, suggesting that apologies can eliminate the negative social consequences of anger altogether.

We found only weak support for the retaliation hypothesis, which predicted that negative impressions instilled by the partner's anger would render participants more demanding in subsequent negotiations. This only occurred among proselfs in the anger-with-apology condition. One might therefore wonder whether retaliation was a viable option, given that participants had to reach an agreement to qualify for a prize. In this respect we note that previous work using comparable paradigms has repeatedly demonstrated retaliatory responses to anger expressions, suggesting that retaliation is indeed an option. Friedman et al. (2004) observed retaliatory responses to verbal expressions of anger in an online dispute resolution study, where failure to reach agreement implied additional costs for mediation services. Other work has documented retaliatory responses to anger expressions in ultimatum bargaining, where failure to reach agreement means that both parties receive nothing (Kopelman et al., 2006; Van Dijk et al., 2008). Van Kleef and Côté (2007) observed retaliatory reactions (i.e., competitive demands) to anger expressions using the present paradigm. Finally, Van Beest and colleagues (2008) found that individuals reacted in a retaliatory fashion (in this case by sabotaging a possible coalition) to partners' verbal expressions of anger during coalition negotiations, even if this diminished their own chances of becoming part of a profitable coalition. The fact that our participants accommodated to their counterpart's anger in the second negotiation despite being tempted to retaliate speaks to the power of the spillover effect.

Exploratory analyses revealed no effects of the partner's anger expression in Negotiation 1 on perceptions of anger after Negotiation $2 .^{2}$ This makes it less likely that the effects of the partner's emotion in Negotiation 1 on demands in Negotiation 2 were due to the

\footnotetext{
2 Experiment 1: $M_{\text {anger }}=3.37, M_{\text {neutral }}=2.92, F(1,71)=1.35$, ns. Experiment 2 $M_{\text {anger }}=3.54, M_{\text {anger+apology }}=3.34, M_{\text {neutral }}=3.34, F(2,91)=.74, n s$.
}

perception that the partner was still angry. It is possible, however, that the effects are partly driven by the inference that the partner might become angry again. This possibility is consistent with the spillover logic, as the person's actual anger on T1 would spill over to create an impression that the other might get angry on $\mathrm{T} 2$, even in the absence of any anger expression. Thus, negotiators may give in to previously angry counterparts to prevent them from getting angry again. New research is needed to examine whether, in addition to inferences about the previously angry partner's limits, lower demands are due also to expectations that the partner is easily provoked.

Our findings add to the growing literature on the social functions of emotions (e.g., Keltner \& Haidt, 1999; Morris \& Keltner, 2000; Parkinson, 1996; Van Kleef, 2009; Van Kleef et al., 2010) by showing that expressions of anger may continue to shape targets' behavior in future interactions, even if the expressions are not repeated. The implications of this notion may reach beyond the negotiation domain and speak to, for instance, parenting, socialization, and leadership. Recent research suggests that the willingness to express negative emotions has beneficial effects in various social situations, such as garnering social support and building friendships (Graham, Huang, Clark, \& Helgeson, 2008). Future research is needed to establish whether the longer-term effects of anger expressions in such settings are different from the effects uncovered here.

Our findings also contribute to the literature on social value orientations. Prosocial negotiators demanded less from a partner who expressed anger and then apologized, whereas proselfs demanded more from an apologetic counterpart. This finding extends theorizing and research on the might/morality effect (Liebrand et al., 1986; Van Lange \& Kuhlman, 1994). Prosocials appear to be more sensitive to the moral aspects of their counterpart's apologies, whereas proselfs are more sensitive to might-related implications. This suggests that the effectiveness of reconciliation attempts and appeasement strategies depends on the recipient's personality, which may explain why apologies sometimes help to restore relationships and sometimes fail to do so (Kim, Ferrin, Cooper, \& Dirks, 2004; Ohbuchi et al., 1989; Schweitzer, Hershey, \& Bradlow, 2006; Struthers et al., 2008). A practical implication is that apologizing to a selfish other entails the risk of being exploited, whereas apologizing to a prosocial other holds the promise of reciprocal cooperation.

We employed a computer-mediated negotiation paradigm to permit a carefully controlled manipulation of the partner's emotional expression, and to allow us to make participants believe that they were dealing with the same or a different partner in the second negotiation while still controlling the partner's behavior. Given this somewhat contrived setting, the question arises whether our findings generalize to situations with greater social richness (e.g., nonverbal cues). Our confidence in the generalizability of the findings is bolstered by prior research on single-shot negotiations, which has found similar effects regardless of whether anger was expressed verbally via computer-mediated communication (Andrade \& Ho, 2007; Friedman et al., 2004; Van Kleef et al., 2004a, 2004b), via facial expressions (Pietroni et al., 2008), via video clips including a mix of verbal and nonverbal expressions (Côté et al., submitted for publication), or via face-to-face communication (Sinaceur \& Tiedens, 2006). Future research is needed to explore this issue in greater depth.

Finally, a word of caution is in place. One should not conclude from these findings that expressing anger is always a good idea, and we are not advising negotiators to express anger strategically. Even though expressions of anger may elicit concessions, they also harm interpersonal relationships. Furthermore, future research is needed to examine whether our findings can be replicated outside the laboratory. Given that previous work on anger in real-life 
settings (Friedman et al., 2004) has produced findings that are consistent with experimental studies (Sinaceur \& Tiedens, 2006; Van Kleef et al., 2004b), we do believe that the mechanisms uncovered here also play a role in real life. Awaiting verification outside the lab, we conclude that the social influence exerted by expressions of anger is not limited to one moment in time but may spill over to shape future interactions.

\section{Acknowledgments}

Preparation of this paper was supported by research grants from the Netherlands Organisation for Scientific Research awarded to the first author (NWO-451-05-010) and the second author (NWO-400-07-701).

\section{References}

Adler, R. S., Rosen, B., \& Silverstein, E. M. (1998). Emotions in negotiation: How to manage fear and anger. Negotiation Journal, 14, 161-180.

Allred, K. G. (1999). Anger and retaliation: Toward an understanding of impassioned conflict in organizations. Research on Negotiation in Organizations, 7, 27-58.

Andrade, E. B., \& Ho, T.-H. (2007). How is the boss's mood today? I want a raise. Psychological Science, 18, 668-671.

Axelrod, R. (1984). The evolution of cooperation. New York: Basic Books.

Bachman, G. F., \& Guerrero, L. K. (2006). Forgiveness, apology, and communicative responses to hurtful events. Communication Reports, 19, 45-56.

Barclay, L. J., Skarlicki, D. P., \& Pugh, S. D. (2005). Exploring the role of emotions in injustice perceptions and retaliation. Journal of Applied Psychology, 90, 629-643.

Baron, R. A., Neuman, J. H., \& Geddes, D. (1999). Social and personal determinants of workplace aggression: Evidence for the impact of perceived injustice and the type A behavior pattern. Aggressive Behavior, 25, 281-296.

Bies, R. J., \& Moag, J. F. (1986). Interactional justice: Communication criteria of fairness. In R. J. Lewicki, B. H. Sheppard, \& M. H. Bazerman (Eds.). Research on negotiations in organizations (Vol. 1, pp. 43-55). Greenwich, CT: JAI Press.

Bies, R. J., \& Tripp, T. M. (2001). A passion for justice: The rationality and morality of revenge. In R. Cropanzano (Ed.). Justice in the workplace: From theory to practice (Vol. 2, pp. 197-208). Mahwah, NJ: Erlbaum.

Clark, M. S., Pataki, S. P., \& Carver, V. H. (1996). Some thoughts and findings on selfpresentation of emotions in relationships. In G. J. O. Fletcher \& J. Fitness (Eds.), Knowledge structures in close relationships: A social psychological approach (pp. 247-274). Mahwah, NJ: Erlbaum.

Clark, M. S., \& Taraban, C. B. (1991). Reactions to and willingness to express emotion in communal and exchange relationships. Journal of Experimental Social Psychology, 27, 324-336.

Côté, S., Van Kleef, G. A., \& Hideg, I. (submitted for publication). Strategic emotion regulation in conflict resolution: Consequences of deep acting and surface acting..

Darby, B. W., \& Schlenker, B. R. (1982). Children's reactions to apologies. Journal of Personality and Social Psychology, 43, 742-753.

De Cremer, D., \& Van Lange, P. A. M. (2001). Why prosocials exhibit greater cooperation than proselfs: The roles of social responsibility and reciprocity. European Journal of Personality, 15, 5-18.

De Dreu, C. K. W. (2010). Social conflict: The emergence and consequences of struggle and negotiation. In S. T. Fiske, D. T Gilbert, \& G. Lindzey (Eds.), Handbook of social psychology (5th ed., Vol. 2, pp. 983-1023). New York: Wiley.

De Dreu, C. K. W., \& Van Kleef, G. A. (2004). The influence of power on the information search, impression formation, and demands in negotiation. Journal of Experimental Social Psychology, 40, 303-319.

De Dreu, C. K. W., \& Van Lange, P. A. M. (1995). The impact of social value orientations on negotiator cognition and behavior. Personality and Social Psychology Bulletin, 21, 1178-1188.

Fischer, A. H., \& Roseman, I. J. (2007). Beat them or ban them: The characteristics and social functions of anger and contempt. Journal of Personality and Social Psychology, 93, 103-115.

Frank, R. H. (1988). Passions within reason: The strategic role of the emotions. New York: Norton.

Friedman, R., Anderson, C., Brett, J., Olekalns, M., Goates, N., \& Lisco, C. C. (2004). The positive and negative effects of anger on dispute resolution: Evidence from electronically mediated disputes. Journal of Applied Psychology, 89, 369-376.

Frijda, N. H. (1986). The emotions. Cambridge: Cambridge University Press.

Graham, S. M., Huang, J. Y., Clark, M. S., \& Helgeson, V. S. (2008). The positives of negative emotions: Willingness to express negative emotions promotes relationships. Personality and Social Psychology Bulletin, 34, 394-406.

Hilty, J. A., \& Carnevale, P. J. (1993). Black-hat/white-hat strategy in bilateral negotiation. Organizational Behavior and Human Decision Processes, 55, 444-469.

Keltner, D., \& Haidt, J. (1999). Social functions of emotions at four levels of analysis. Cognition and Emotion, 13, 505-521.

Kennedy, D. B., Homant, R. J., \& Homant, M. R. (2004). Perception of injustice as a predictor of support for workplace aggression. Journal of Business and Psychology, 18, 323-336.
Kenny, D. A., Kashy, D. A., \& Bolger, N. (1998). Data analysis in social psychology. In D. T. Gilbert, S. T. Fiske, \& A. Lindzey (Eds.). The handbook of social psychology (Vol. 1, pp. 233-265). Boston: McGraw-Hill.

Kim, P. H., Ferrin, D. L., Cooper, C. D., \& Dirks, K. T. (2004). Removing the shadow of suspicion: The effects of apology versus denial for repairing competence- versus integrity-based trust violations. Journal of Applied Psychology, 89, 104-118.

Kopelman, S., Rosette, A. S., \& Thompson, L. (2006). The three faces of eve: An examination of the strategic display of positive, negative, and neutral emotions in negotiations. Organizational Behavior and Human Decision Processes, 99, 81-101.

Lazarus, R. S. (1991). Emotion and adaptation. New York: Oxford University Press.

Liebrand, W. B., Jansen, R. W., Rijken, V. M., \& Suhre, C. J. (1986). Might over morality: Social values and the perception of other players in experimental games. Journal of Experimental Social Psychology, 22, 203-215.

Liebrand, W. B. G., \& Van Run, G. (1985). The effects of social motives across two cultures on behavior in social dilemmas. Journal of Experimental Social Psychology, 21, 86-102.

Messick, D. M., \& McClintock, C. G. (1968). Motivational bases of choice in experimental games. Journal of Experimental Social Psychology, 4, 1-25.

Morris, M. W., \& Keltner, D. (2000). How emotions work: An analysis of the social functions of emotional expression in negotiations. Research in Organizational Behavior, 22, 1-50.

Morris, M. W., Larrick, R. P., \& Su, S. K. (1999). Misperceiving negotiation counterparts: When situationally determined bargaining behaviors are attributed to personality traits. Journal of Personality and Social Psychology, 77, $52-67$

Ohbuchi, K., Kameda, M., \& Agarie, N. (1989). Apology as aggression control: Its role in mediating appraisal of and response to harm. Journal of Personality and Social Psychology, 56, 219-227.

Olekalns, M., \& Smith, P. L. (1999). Social value orientations and strategy choices in competitive negotiations. Personality and Social Psychology Bulletin, 25, 657-668.

Parkinson, B. (1996). Emotions are social. British Journal of Psychology, 87, 663-683.

Philpot, C. R., \& Hornsey, M. J. (2008). What happens when groups say sorry: The effect of intergroup apologies on their recipients. Personality and Social Psychology Bulletin, 34, 474-487.

Pietroni, D., Van Kleef, G. A., De Dreu, C. K. W., \& Pagliaro, S. (2008). Emotions as strategic information: Effects of other's emotions on fixed-pie perception, demands and integrative behavior in negotiation. Journal of Experimental Social Psychology, 44, 1444-1454.

Ross, L. D. (1977). The intuitive psychologist and his shortcomings: Distortions in the attribution process. In L. Berkowitz (Ed.). Advances in experimental social psychology (Vol. 10, pp. 173-220). New York: Academic Press.

Schweitzer, M. E., Hershey, J. C., \& Bradlow, E. T. (2006). Promises and lies: Restoring violated trust. Organizational Behavior and Human Decision Processes, 101, 1-19.

Sinaceur, M. \& Tiedens, L. Z. (2006). Get mad and get more than even: When and why anger expression is effective in negotiations. Journal of Experimental Social Psychology, 42, 314-322.

Skarlicki, D. P., \& Folger, R. (1997). Retaliation in the workplace: The roles of distributive, procedural, and interactional justice. Journal of Applied Psychology, 82, 434-443.

Steinel, W., \& De Dreu, C. K. W. (2004). Social motives and strategic misrepresentation in social decision making. Journal of Personality and Social Psychology, 86, 419-434.

Steinel, W., Van Kleef, G. A., \& Harinck, F. (2008). Are you talking to me?! Separating the people from the problem when expressing emotions in negotiation. Journal of Experimental Social Psychology, 44, 362-369.

Steiner, C. (2000). Apology: The transactional analysis of a fundamental exchange. Transactional Analysis Journal, 30, 145-149.

Struthers, C. W., Eaton, J., Santelli, A. G., Uchiyama, M., \& Shirvani, N. (2008). The effects of attributions of intent and apology on forgiveness: When saying sorry may not help the story. Journal of Experimental Social Psychology, 44, 983-992.

Tavuchis, N. (1991). Mea culpa: A sociology of apology and reconciliation. Stanford, CA: Stanford University Press.

Tiedens, L. Z. (2001). Anger and advancement versus sadness and subjugation: The effect of negative emotion expressions on social status conferral. Journal of Personality and Social Psychology, 80, 86-94.

Tinsley, C. H., O'Connor, K. M., \& Sullivan, B. A. (2002). Tough guys finish last: The perils of a distributive reputation. Organization Behavior and Human Decision Processes, 88, 621-642.

Van Beest, I., Van Kleef, G. A., \& Van Dijk, E. (2008). Get angry, get out: The interpersonal effects of anger communication in multiparty negotiation. Journal of Experimental Social Psychology, 44, 993-1002.

Van Dijk, E., Van Kleef, G. A., Steinel, W., \& Van Beest, I. (2008). A social functional approach to emotions in bargaining: When communicating anger pays and when it backfires. Journal of Personality and Social Psychology, 94, 600-614.

Van Kleef, G. A. (2009). How emotions regulate social life: The emotions as social information (EASI) model. Current Directions in Psychological Science, 18, 184-188.

Van Kleef, G. A., \& Côté, S. (2007). Expressing anger in conflict: When it helps and when it hurts. Journal of Applied Psychology, 92, 1557-1569.

Van Kleef, G. A., De Dreu, C. K. W., \& Manstead, A. S. R. (2004a). The interpersonal effects of anger and happiness in negotiations. Journal of Personality and Social Psychology, 86, 57-76.

Van Kleef, G. A., De Dreu, C. K. W., \& Manstead, A. S. R. (2004b). The interpersonal effects of emotions in negotiations: A motivated information processing approach. Journal of Personality and Social Psychology, 87, 510-528. 
Van Kleef, G. A., De Dreu, C. K. W., \& Manstead, A. S. R. (2010). An interpersonal approach to emotion in social decision making: The emotions as social information model. Advances in Experimental Social Psychology, 42, 45-96.

Van Kleef, G. A., Homan, A. C., Beersma, B., van Knippenberg, D., van Knippenberg, B. \& Damen, F. (2009). Searing sentiment or cold calculation? The effects of leader emotional displays on team performance depend on follower epistemic motivation. Academy of Management Journal, 52, 562-580.

Van Kleef, G. A., \& Van Lange, P. A. M. (2008). What other's disappointment may do to selfish people: Emotion and social value orientation in a negotiation context. Personality and Social Psychology Bulletin, 34, 1084-1095.
Van Lange, P. A. M. (1999). The pursuit of joint outcomes and equality in outcomes: An integrative model of social value orientation. Journal of Personality and Social Psychology, 77, 337-349.

Van Lange, P. A. M., \& Kuhlman, D. M. (1994). Social value orientations and impressions of partner's honesty and intelligence: A test of the might versus morality effect. Journal of Personality and Social Psychology, 67, 126-141.

Van Lange, P. A. M., Otten, W., De Bruin, E. N. M., \& Joireman, J. A. (1997) Development of prosocial, individualistic, and competitive orientations: Theory and preliminary evidence. Journal of Personality and Social Psychology, 73, 733-746. 